\title{
A CASE STUDY IN EVOLUTIONARY CONTINGENCY
}

ZACHARY D. BLOUNT ${ }^{1,2}$

\author{
1. BEACON Center for the Study of Evolution in Action, Michigan State \\ University, East Lansing, MI, USA \\ 2. Department of Microbiology and Molecular Genetics, Michigan State \\ University, East Lansing, MI, USA
}

\section{ACKNOWLEDGEMENTS}

I would like to thank Richard Lenski and Neerja Hajela for years of support and guidance; Justin Meyer, John Beatty, Robert Pennock, David Bryson, Jessica Plucain, Sabrina Mueller-Spitz, Brian Wade, Betül Kaçar, and Rohan Maddamsetti for helpful advice and discussions; Chris Borland, Jeff Barrick, Carla Davidson, Daniel Deatherage, Andrew Ellington, George Georgiou, Jimmy Golihar, Mark Kauth, Dacia Leon, Daniel Mitchell, Erik Quandt, Maia Rowles, Brooke Sommerfeld, Caroline Turner, Kiyana Weatherspoon, and Jacob Wright for their contributions to the citrate project; and the members of the lab's support staff over the years, including Brian Baer, Brian Chernoff, Florence Emananjo, Marwa Adawe, Michele Mize, Camorrie Bradley, Pa Vang, Rafael Martinez, and Jamie Johnson. The work discussed in this paper was supported by a John Templeton Foundation Foundational Questions in Evolutionary Biology grant (FQEB \#RFP-12-13), the BEACON Center for the Study of Evolution in Action (NSF Cooperative Agreement DBI-0939454), the Defense Advanced Research Projects Agency (HR0011-09-1-0055), the U.S. National Science Foundation (NSF; DEB- 
1019989), a Rudolf Hugh Fellowship, a DuVall Family Award, a Ronald M. and Sharon Rogowski Fellowship, and a Barnett Rosenberg Fellowship.

\begin{abstract}
Biological evolution is a fundamentally historical phenomenon in which intertwined stochastic and deterministic processes shape lineages with long, continuous histories that exist in a changing world that has a history of its own. The degree to which these characteristics render evolution historically contingent, and evolutionary outcomes thereby unpredictably sensitive to history has been the subject of considerable debate in recent decades. Microbial evolution experiments have proven among the most fruitful means of empirically investigating the issue of historical contingency in evolution. One such experiment is the E. coli Long-Term Evolution Experiment (LTEE), in which twelve populations founded from the same clone of E. coli have evolved in parallel under identical conditions. Aerobic growth on citrate $\left(\mathrm{Cit}^{+}\right)$, a novel trait for $E$. coli, evolved in one of these populations after more than 30,000 generations. Experimental replays of this population's evolution from various points in its history showed that the $\mathrm{Cit}^{+}$trait was historically contingent upon earlier mutations that potentiated the trait by rendering it mutationally accessible. Here I review this case of evolutionary contingency and discuss what it implies about the importance of historical contingency arising from the core processes of evolution.
\end{abstract}

Keywords: Historical Contingency; Evolutionary Contingency; Evolutionary Novelty; Experimental Evolution; E. coli; Long-Term Evolution Experiment 
History is subject to a tangled tension between chance and necessity. Humans have long been conscious of this fact, with one consequence being that human conceptions of history have generally fallen on a continuum between extreme poles that may be thought of as fate and fortune. In Greco-Roman mythology, fate is personified as the three stern Fates who see that history unfolds inevitably according to their inflexible plan. Fortune is personified by Fortuna, the goddess of luck and the "million to one shot." Whereas the Fates are steady and implacable beings, the workings of whom cannot be altered even by the gods themselves, Fortuna is fickle, plays favorites as she pleases, and can whimsically change the course of events at any time. In the fatalistic view, historical outcomes are inevitable and predetermined, whereas in the view governed by fortune no historical event is inevitable until it has occurred, because chance can always intervene. Of course, both polar extremes are problematic, and most take a mixed view between the two.

Like human history, biological evolution is also subject to a tension between chance and necessity. Its core processes involve a complex interplay of the random and the deterministic (Monod 1971). Natural selection works deterministically to adapt populations to their environments, but it must act upon heritable variation stochastically introduced by random mutation, gene flow, and recombination. Beneficial variation introduced by any of these mechanisms may be lost at random by genetic drift. Mutations can vary greatly in their effects on multiple traits (pleiotropy) and in their interactions with other genes (epistasis), so that the order in which beneficial mutations arise can change the fitness value of subsequent mutations (Mani and Clarke 1990; Lenski et al. 1991). Due to these effects, populations starting from the same ancestral genotype can 
evolve along divergent paths that vary in their evolutionary potential, thereby making evolutionary outcomes path dependent to at least some degree (Wright 1988; Cooper and Lenski 2000; Weinreich, Watson, and Chao 2005; Weinreich et al. 2006). For instance, different evolutionary paths can lead to states with similar fitness in a prevailing environment, but very different fitness in other environments. Seemingly subtle differences between lineages can determine which go extinct and which survive during periods of rapid and capricious environmental change (Lewontin 1966; Gould 1985; Jablonski 1986).

All modern organisms are the products of unique, unbroken, and very long evolutionary histories that have played out within the broader history of a changing Earth. How important is this fact? Stephen Jay Gould suggested that it is very important. Gould focused on instances such as the body plan diversity evident in the fossils of the Burgess Shale, only a subset of which continue to exist, to suggest that there were viable alternate routes evolution could have taken (Gould 1989, esp. 299-321, 1991, 2002, 1159-60). In Gould's view, evolution followed the path it did due in large measure to chance, including that imparted by capricious mass extinction events like the KT impact (Gould 1989, 305-8, 2002, 1315-20). He argued that such cases show that evolutionary outcomes are sensitive to the peculiarities and quirks of history, making them fundamentally contingent, unpredictable, and path dependent (Gould 1989, 45-52, chap. 5, 2002, chap. 12; Beatty 2006; Beatty and Carrera 2011). Famously, Gould suggested in Wonderful Life $(1989,48-51)$ that this contingency means that replaying the "tape of life" from points in the distant past would result in living worlds far different than the one that now exists, because evolution would be unlikely to follow the same path twice. 
Gould's position has been controversial. Simon Conway Morris and others have pointed to the striking pervasiveness of convergent evolution as suggesting that natural selection and biological and physical constraints greatly restrict the range of viable evolutionary outcomes (Conway Morris 2003, 2010; Van Valen 1991; Dawkins 1996; Vermeij 2006). As Conway Morris writes in Life's Solution (2003, 144), "the evolutionary routes are many, but the destinations are limited." If there are few viable end points, and the origin of life always leads to elephants, then evolution is relatively path independent (Atkins 1981, 3). As in a Greek tragedy, the only uncertainty is that of how evolution reaches its inevitable end. In this view, replaying the tape of life would always lead to remarkably similar outcomes.

This debate has major implications for how evolution should be understood and explained as a phenomenon (Beatty 1993; Sterelny and Griffiths 1999; Desjardins 2011). If evolution is highly path dependent, with many viable outcomes, then evolution must be understood in a narrative fashion (Blaser 1999; Gould 1985, 1989, 2002). However, if evolution's path dependence is highly constrained by few viable end states, then evolution is predictable and can be understood using robust process explanations insensitive to history, such as those in physics (Sterelny and Griffiths 1999, 84-86). As John Beatty makes clear in his article in this issue, a narrative requires that there be possible alternatives, but if the ends of evolution are largely invariant, then narrative explanations are not appropriate.

Scientific debates must ultimately be resolved by empirical research that adjudicates which side better describes the underlying reality, and the contingency debate is no different. Gould's and Conway Morris's work does contribute to this resolution, but 
not directly. Each marshalled facts and findings that serve to argue for the plausibility of their respective positions (Gould 1989; Conway Morris 2003, 2010). Their work therefore principally serves to lay out broad lines from which other researchers may develop better definitions, more focused models, and, importantly, testable hypotheses. Indeed, Gould's and Conway Morris's work has been a springboard from which numerous researchers have begun to evaluate the complex questions of evolutionary contingency (Orgogozo 2015). Appropriately, these empirical studies have examined contingency on multiple levels, including Vermeij's examination of the timing and phylogenetic distribution of evolutionary innovations (2006), examination of natural instances of "replaying the tape" such as radiations of Anolis lizards on Caribbean islands (Losos et al. 1998; Losos 2010), and investigation of the effects of history on the evolution of egg-eating snakes (de Queiroz and Rodriguez-Robles 2006) and Southeast Asian fanged frogs (Emerson 2001). These empirical studies have made substantial contributions to a better understanding of evolutionary contingency and convergence within the context of the natural world. At the other end of the spectrum, a great deal of intriguing work has been done using experimental microbial evolution systems, in which the loss of complexity is balanced by the ability to evaluate directly the effects of history on evolution.

\section{EXPERIMENTAL EVOLUTION WITH MICROORGANISMS}

Experimental evolution with microorganisms involves propagating populations of microbes under controlled conditions to examine evolution as it occurs (Elena and Lenski 2003; Kawecki et al. 2012). This approach to studying evolution was first used by 
William Henry Dallinger, an English Methodist minister and correspondent of Darwin's, in work he did in the 1880's that examined the evolution of thermotolerance by pond organisms (1887). Despite this early start, experimental evolution with microorganisms only began to be used as a major research approach in the 1980s, and it has since proven to be a powerful way to address a variety of fundamental questions in evolutionary biology that are difficult to examine using more traditional techniques (Elena and Lenski 2003; Kawecki et al. 2012; Kaçar and Gaucher 2013; Kussell 2013).

There are many benefits to using microbes to study evolution. Microbes reproduce very quickly, making it possible to study hundreds or thousands of generations of evolution in experiments lasting only weeks or years. Large population sizes provide a steady influx of new variation from mutations. High levels of experimental replication are possible because these large populations can be kept in small containers. (A $10 \mathrm{~mL}$ bacterial culture may contain up to $5 \times 10^{10}$ cells.) Microbes reproduce asexually, so genetically identical replicate populations can be founded. A high level of control is also possible because microbial cultures are easily maintained under a variety of conditions. Moreover, researchers can reliably manipulate important factors such as mutation supply, population size, prior evolutionary history, and the biotic and abiotic environment to study their effects (Chao and Cox 1983; Burch and Chao 2000a, 2000b; de Visser et al. 1999; Elena et al. 2001; Perfeito et al. 2007; Travisano et al. 1995; Lenski and Levin 1985; Bennett and Lenski 1993; Bohannan and Lenski 2000; Fukami et al. 2007; Meyer and Kassen 2007). Perhaps just as importantly, a wealth of tools, including genome sequencing and genetic engineering, allow researchers to identify evolved genetic changes and directly link them to phenotypic changes (Herring, Glasner, and Blattner 
2003; Bentley 2006; Hegreness and Kishony 2007; Barrick et al. 2009; Barrick and Lenski 2009). Finally, microorganisms can be frozen indefinitely without loss of viability, so that ancestral and evolved clones ${ }^{1}$ and populations are available for revival at will.

A number of these advantages make experimental evolution with microbes particularly useful for studying contingency. Genetically identical replicates allow the repeatability of evolution to be assessed using replicate populations that evolve in parallel from the same genetic starting point. This means that the tape of life can actually be replayed, albeit on a smaller scale than Gould envisioned (Blount, Borland, and Lenski 2008; Turner et al. 2015; Blount, Forthcoming). The capacity to identify mutations and link them to phenotypes means that divergence and convergence can be studied on an extremely granular scale. Moreover, the frozen fossil records of experimental populations provide a level of direct access to populations' evolutionary history that is unthinkable in other systems, providing for highly detailed reconstructions of history, and also close study of the effects of historical events. These advantages permit microbial evolution experiments to approach multiple aspects and concepts of contingency in ways that are impossible with natural populations or paleontological data (Beatty 2006; Beatty and Carrera 2011; Turner et al. 2015; Blount, Forthcoming). Many recent experimental evolution studies have addressed evolutionary contingency using a variety of approaches and model organisms (Travisano et al. 1995; Travisano, Vasi, and Lenski 1995; Fukami et al. 2007; Cooper and Lenski 2010; Chen, Jewett, and Groisman 2011; Meyer et al. 2012; Flores-Moya et al. 2012; Bedhomme, Lafforgue, and Elena 2013; Szendro et al. 2013; Spor et al. 2014; Blount, Forthcoming). Here I will focus on the findings and 
implications of my own work on a historically contingent key adaptation that arose in the course of one of the longest-running microbial evolution experiments to date.

\section{THE E. COLI LONG-TERM EVOLUTION EXPERIMENT (LTEE)}

Richard Lenski began the LTEE on February 24, 1988. The experiment is remarkably simple (Fig. 1). Twelve replicate populations were all founded from the same strain of $E$. coli. Each day, one percent of each population is transferred into a fresh volume of a growth medium called DM25, which contains a small amount of glucose and all other nutrients necessary for bacterial growth (Davis and Mingioli 1950). Under these conditions, each population grows one hundred-fold each day, or about 6.6 generations (Lenski et al. 1991; Lenski 2004). The experiment will celebrate its twenty-eighth year in February 2016, and each population has so far evolved for more than sixty thousand generations. Population samples are frozen for the fossil record every five hundred generations.

The LTEE examines evolution under very simple conditions (Lenski et al. 1991; Lenski and Travisano 1994; Lenski 2004; Fox and Lenski 2015). The founding clone is strictly asexual (Jeong et al. 2009; Studier et al. 2009). The populations each evolve in complete isolation, with no possibility of gene flow from other populations or sources. Evolution in the LTEE therefore involves only random genetic drift and natural selection acting on variation generated by spontaneous mutation (Lenski et al. 1991; Lenski 2004). Moreover, the environment is kept very stable. Aside from the brief period the populations spend at room temperature during transfers, the only environmental variation they experience is the regular daily "seasonality" of feast upon transfer to fresh medium, 
followed by glucose exhaustion, and any other bacterial modification of the medium such as the excretion of metabolic byproducts.

One of the LTEE's principal goals was to examine evolutionary repeatability, and its structure reflects this goal (Lenski et al. 1991; Lenski 2004; Fox and Lenski 2015). Because all populations began from the same genetic state, and have been maintained under identical conditions, the LTEE essentially involves replaying the same tape of life twelve times simultaneously. This design makes the LTEE what may be called a "parallel replay experiment," ${ }^{2}$ which permits it to be used to examine the effects of historical differences arising from the core evolutionary processes (Blount, Forthcoming). If evolution were fundamentally repeatable, and the vagaries of the evolutionary history of each population were not relevant, then all twelve populations should evolve essentially in parallel, with each finding the same adaptations, pursuing the same fitness track, and evolving very similar phenotypes and population structures over time. On the other hand, were those historical vagaries important, then the populations should follow distinct evolutionary paths, and so diverge significantly and meaningfully over time (Lenski et al. 1991; Lenski 2004).

The populations have shown extensive parallel evolution. All have evolved much higher fitness than the ancestor under the experimental conditions (Lenski and Travisano 1994; Lenski 2004; Wiser et al. 2013; Lenski et al., In press). The populations have all evolved faster growth on glucose, larger cell size, smaller maximum population sizes, and greater ecological specialization (Lenski and Travisano 1994; Vasi, Travisano, and Lenski 1994; Cooper and Lenski 2000; Cooper et al. 2001; Lenski 2004; Philippe et al. 2009; Leiby and Marx 2014). They have evolved similar changes in gene expression and 
regulation (Cooper, Rozen, and Lenski 2003; Cooper et al. 2008; Crozat et al. 2011; Philippe et al. 2007), protein content (Pelosi et al. 2006), and resistance to certain viruses (Meyer et al. 2010). Most of the populations have also evolved similar changes in DNA topology (Crozat et al. 2005; 2010). Finally, a number of the same genes have accumulated mutations in some or all of the populations (Barrick et al. 2009; Cooper et al. 2001; Crozat et al. 2005; Crozat et al. 2010; Cooper, Rozen, and Lenski 2003; Pelosi et al. 2006; Philippe et al. 2009; Woods et al. 2006). Several of these parallel mutations demonstrably increase fitness under LTEE conditions (Barrick et al. 2009; Cooper et al. 2001; Lenski et al. 2003; Philippe et al. 2009).

The populations have also diverged evolutionarily. Each population has accumulated different sets of mutations (Woods et al. 2006; Stanek 2009). Even among genes that have mutated in parallel across multiple populations, the locations and details of the mutations are rarely identical (Crozat et al. 2005; Cooper, Rozen, and Lenski 2003; Pelosi et al. 2006; Woods et al. 2006; Cooper et al. 2001). Each population has also accumulated different gross changes to their genome, including IS insertions, inversions, and deletions (Papadopoulos et al. 1999). About half of the populations have evolved high mutation rates due to mutations in DNA repair genes, which have accelerated genomic divergence (Sniegowski, Gerrish, and Lenski 2000; Barrick and Lenski 2009; Barrick et al. 2009; Blount et al. 2012). Subtle, but significant and persistent variation in fitness has also been detected among the populations, suggesting that they may be climbing different adaptive peaks (Lenski et al. 1991; Lenski and Travisano 1994, Lenski et al., In press). While unused functions have decayed across all populations, this decay 
varies among populations, and some populations have even seen functional gains (Cooper and Lenski 2000; Leiby and Marx 2014).

More meaningful instances of divergence have also been observed. Perhaps the most significant is the population called Ara-2, in which two lineages, "S" and "L," have coexisted for more than fifty thousand generations (Rozen and Lenski 2000; Rozen, Schneider, and Lenski 2005; le Gac et al. 2012; Plucain et al. 2014). This coexistence is maintained by the S cells cross-feeding on metabolic byproducts of the L cells, which grow better on the glucose in the medium, but die at higher rates after glucose runs out (Rozen et al. 2009). The origins of this interaction are still under study, but they appear to have involved multiple mutational steps taken prior to generation number 6,500 (Plucain et al. 2014). Instances of transient diversity have also been identified in other populations, and it is likely that other examples will be identified in more populations as they are examined more intensively (Elena and Lenski 2003; Barrick et al. 2009; Maddamsetti et al. 2015).

The Ara-2 population aside, the simple glucose environment of the LTEE may have contributed to the parallelism seen in the LTEE. An environment with only one major and easily pursued ecological opportunity makes parallel evolution more likely. Moreover, the extensive parallelism with more subtle divergence in the LTEE suggests that the ancestor was predisposed to adapt to this opportunity, to climb "Mount Glucose," and apparently to do so via a few relatively similar evolutionary paths. However, one population found an alternate path that took it up another mountain altogether. 


\section{THE EVOLUTION OF AEROBIC CITRATE UTILIZATION}

From the beginning, the LTEE has contained an open ecological opportunity created by an abundant resource the bacteria cannot access. In addition to glucose, DM25 medium contains a potential second food source in the form of a high concentration of citrate, ${ }^{3}$ the same substance that makes citrus fruits tart. Unlike many bacteria, however, E. coli cannot grow on citrate under the oxygen-rich conditions of the experiment. This $\mathrm{Cit}^{-}$ phenotype is one of the defining features of $E$. coli as a species (Koser 1924; Lutgens and Gottschalk 1980; Scheutz and Strockbine 2005). E. coli is not metabolically inert toward citrate. It has a complete Krebs, or tri-carboxylic acid cycle, the metabolic pathway by which citrate is metabolized, and citrate is metabolized as an intermediate during aerobic growth on other substances (Lara and Stokes 1952; Lutgens and Gottschalk 1980). Most E. coli strains can also ferment citrate under conditions when oxygen is not present (Lutgens and Gottschalk 1980).

The only known barrier to aerobic growth on citrate is the inability to transport citrate into the cell when oxygen is present (Hall 1982; Reynolds and Silver 1983; Pos, Dimroth, and Bott 1998). E. coli has a citrate transporter, called CitT, but it is expressed only when no oxygen is present (Pos, Dimroth, and Bott 1998). It would seem that evolving an aerobic citrate-using, or $\mathrm{Cit}^{+}$, phenotype would be a relatively simple matter of altering the $c i t T$ gene's regulation. Nonetheless, spontaneous $\mathrm{Cit}^{+}$mutants of $E$. coli are extraordinarily rare. Only one spontaneous $\mathrm{Cit}^{+}$mutant of $E$. coli was reported over the entire twentieth century (Hall 1982). Moreover, while $\mathrm{Cit}^{+}$E. coli strains have been isolated from the environment, they have all been found to carry plasmids from which 
foreign citrate transporters were expressed (Ishiguro, Oka, and Sato 1978; Ishiguro et al. 1979). Clearly, the evolution of a $\mathrm{Cit}^{+}$trait is more difficult than it would first appear. In early 2003, after more than thirty-three thousand generations of evolution, one population, called Ara-3, suddenly got several-fold larger, and its culture much cloudier, as shown in Figure 2 (Blount, Borland, and Lenski 2008). Further study showed that the population was full of $\mathrm{Cit}^{+}$cells that could grow in media that contained citrate as the only available food source. Despite initial fears of contamination, the $\mathrm{Cit}^{+}$cells showed a number of traits and mutations peculiar to the Ara -3 population. The conclusion was inescapable: a $\mathrm{Cit}^{+}$variant had spontaneously evolved. Later investigation showed that the $\mathrm{Cit}^{+}$trait first evolved sometime between 31,000 and 31,500 generations. Early $\mathrm{Cit}^{+}$ variants grew very weakly on citrate, and so they remained a tiny minority in the population. Natural selection gradually refined the $\mathrm{Cit}^{+}$trait over the next 2,500 generations until strongly $\mathrm{Cit}^{+}$variants evolved that were able to rise to high frequency in the population, causing the population expansion that clued us in to the metabolic innovation's evolution (Blount, Borland, and Lenski 2008; Blount et al. 2012).

The $\mathrm{Cit}^{+}$trait has been the most significant evolutionary change observed during the LTEE so far, and it has proven to be the proverbial gift that keeps on giving. It is a key adaptation that presents a chance to study the origins of evolutionary novelty, and how bacteria adapt to new niches and resources. $\mathrm{A} \mathrm{Cit}^{-}$subpopulation persisted as a small minority in the population after $\mathrm{Cit}^{+}$became dominant, which provides an opportunity to examine a new ecology as it evolves (Turner et al., In Review). $\mathrm{Cit}^{+}$also transcends the accepted range of variation for $E$. coli, and might just be an incipient species that could be used to examine speciation - what Darwin and Herschel called "that mystery of 
mysteries"- in a highly characterized and easily manipulated system. Finally, $\mathrm{Cit}^{+}$is a rare instance in which the evolutionary contingency of a novel trait can be empirically assessed. The remainder of this paper will focus on this aspect of $\mathrm{Cit}^{+}$evolution and its broader implications.

\section{Cit $^{+}$IS A HISTORICALLY CONTINGENT TRAIT}

Perhaps the most intriguing and important question about the evolution of $\mathrm{Cit}^{+}$is also the most obvious. The enormous citrate resource had been there from the LTEE's beginning. So why did the $\mathrm{Cit}^{+}$trait evolve only once, and then only after such a long time? One plausible explanation is that $\mathrm{Cit}^{+}$was a historically contingent trait. Historically contingent traits require particular, non-guaranteed antecedent states, which is to say a particular history, to evolve. Their origins are therefore complex, and require multiple mutational steps. Some of these steps may be neutral, not uniquely beneficial ${ }^{4}$, or possibly even mildly detrimental. Because the required steps are not uniquely favored, cumulative selection cannot predictably and rapidly facilitate their accumulation (Dawkins 1996, 45). Instead, the accumulation of the necessary mutations must be an accident of an organism's history. As a consequence, historically contingent traits should typically display two characteristics. First, they will rarely evolve multiple times independently simply because the necessary historical sequences are unlikely to recur (Vermeij 2006). Second, because natural selection cannot construct them directly, contingent traits will tend to arise long after the ecological opportunity or environmental challenge to which they provide adaptation appears (Foote 1998). 
$\mathrm{Cit}^{+}$displays both characteristics expected of historically contingent traits. My colleagues and I therefore hypothesized that the $\mathrm{Cit}^{+}$trait required multiple mutations to evolve: a final one that immediately caused the switch from $\mathrm{Cit}^{-}$to $\mathrm{Cit}^{+}$, and one or more earlier "potentiating" mutations. Under this hypothesis, $\mathrm{Cit}^{+}$arose in Ara -3 because the potentiating mutations happened to accumulate during the population's history, and the long delay was because natural selection did not necessarily favor their accumulation. This hypothesis predicts that the rate at which $\mathrm{Cit}^{+}$mutants arose should have changed over time in Ara-3, rising from the vanishingly low ancestral rate to that of the final mutation needed for the switch from $\mathrm{Cit}^{-}$to $\mathrm{Cit}^{+}$upon the accumulation of the necessary potentiating mutations. That is to say that the potential to evolve $\mathrm{Cit}^{+}$changed over time.

In most cases, a hypothesis that posits that a given evolutionary event was contingent upon a prior event would be difficult, if not impossible, to test without a time machine. Fortunately the LTEE has features that allow historical hypotheses to be tested without pleading with the Doctor for the use of his TARDIS. The experiment's frozen fossil record means that we have something most evolutionary biologists do not: direct access to the population's history, and indeed to actual historical organisms. This access allowed us to conduct experiments that directly evaluated how the potential to evolve $\mathrm{Cit}^{+}$ changed over time. In these experiments we isolated a variety of historical clones from Ara-3's fossil record, used them to found new populations, and then actually replayed the tape of life. If $\mathrm{Cit}^{+}$had in fact been contingent upon earlier potentiating mutations, then $\mathrm{Cit}^{+}$re-evolution would tend to occur in populations founded from later generation clones in which those mutations were present. 
We performed two types of replay experiments (Blount, Borland, and Lenski 2008). In the first, we isolated $\mathrm{Cit}^{-}$clones from twelve points in the population's history between 0 and 32,500 generations, and used them to found 72 new populations that we evolved for 3,700 generations under LTEE conditions. I think of this as the "elegant way" of replaying the tape because it more or less replicated the conditions under which $\mathrm{Cit}^{+}$ initially evolved. Consistent with our hypothesis, $\mathrm{Cit}^{+}$re-evolved four times, each time in a population founded from generation 30,500 or later.

The first replay experiment took more than two years to perform. (While relatively fast, evolution experiments can still take a solid chunk of time.) During this time, we also replayed the tape a second way that involved plating massive numbers of cells on petri plates on which only rare $\mathrm{Cit}^{+}$mutants would form colonies. This "brute force" approach allowed us to quickly examine more clones more extensively than the design of the first experiment permitted. In all, we examined more than $4.0 \times 10^{13}$ cells. As in the first experiment, we found that clones from later generations have a much higher propensity to produce $\mathrm{Cit}^{+}$mutants. Indeed, $\mathrm{Cit}^{+}$never re-evolved from any clone isolated from earlier than 20,000 generations.

Consistent with the historical contingency hypothesis, the replay experiments showed that the potential to evolve the $\mathrm{Cit}^{+}$trait increased markedly over Ara-3's history. To quantify this "potentiation" effect, we used fluctuation tests to compare the rate of mutation to $\mathrm{Cit}^{+}$for the ancestral clone, REL606, with that of the clones that had yielded $\mathrm{Cit}^{+}$mutants during the replay experiments (Luria and Delbrück 1943). In all, we tested around $8.4 \times 10^{12}$ ancestral cells, and observed no $\mathrm{Cit}^{+}$mutants. This result corresponds to an estimated upper bound of less than about $3.6 \times 10^{-13}$ mutations to $\mathrm{Cit}^{+}$per cell per 
generation, which is among the lowest mutation rates ever empirically estimated. By

contrast, we measured the rate of mutation to $\mathrm{Cit}^{+}$in a potentiated genetic background to be approximately $6.6 \times 10^{-13}$ per cell per generation. This is still a remarkably low rate that is about three orders of magnitude below the typical mutation rate in E. coli (Drake 1991). The potentiating mutations therefore boosted the rate of mutation to $\mathrm{Cit}^{+}$from an inaccessibly low ancestral rate of "approximately never" to a still very low, but accessible rate of "approximately almost never."

\section{GENOMIC ANALYSIS OF Cit ${ }^{+}$}

The $\mathrm{Cit}^{+}$trait was contingent upon the prior evolutionary history of the Ara-3 population, but what was this history? What mutations and evolutionary paths led to the $\mathrm{Cit}^{+}$trait and its eventual evolutionary success? As I will discuss below, answering these questions is a bit more difficult than it might seem, but the first step in doing so is to consult the single relevant historical record: the evolving population's genomic annals, in which genetic changes were recorded in the organisms' DNA. We took advantage of the recent revolution in DNA sequencing technology to obtain the complete sequences of the genomes of twenty-nine clones isolated from various points in Ara-3's history, and identified almost all of the mutations that had accumulated in each (Blount et al. 2012).

We first used these genomic data to reconstruct the population's phylogeny, which showed that Ara-3 had been diverse over most of its history (Fig. 3). At least three clades, or related lineages, called Clades 1,2, and 3, had evolved by generation 20,000, and then co-existed until after $\mathrm{Cit}^{+}$became dominant some 14,000 generations later. The $\mathrm{Cit}^{+}$lineage itself diverged from Clade 3 after 31,000 generations. The phylogeny also 
provided guidance in our search for mutations involved in $\mathrm{Cit}^{+}$evolution. These mutations seem to have accumulated in three distinct phases. The first to accumulate were those that potentiated $\mathrm{Cit}^{+}$evolution by making the trait mutationally reachable. $\mathrm{A}$ final mutation then actualized the trait, causing a qualitative switch from $\mathrm{Cit}^{-}$to weakly $\mathrm{Cit}^{+}$. Finally, mutations that refined the weak $\mathrm{Cit}^{+}$trait into a stronger form accumulated through the action of natural selection.

Actualization was the most straightforward of the phases to figure out. All $\mathrm{Cit}^{+}$ genomes have a genetic duplication that contains the $\operatorname{cit} T$ gene, which encodes the CitT citrate transporter protein that pumps citrate into the cell during anaerobic growth on citrate, as shown in figure 4 (Pos, Dimroth, and Bott 1998). This duplication is what immediately caused the $\mathrm{Cit}^{+}$trait. To understand how, it is first important to know that DNA sequences called promoters regulate when a cell turns genes on and off. For the most part, which promoter controls which gene is determined by their spatial relationship. The cit $T$ gene is normally controlled by a promoter that only turns the gene on when no oxygen is present. The duplication changes this regulation by placing a new copy of citT next to and under the control of a promoter that normally turns the rnk gene on when oxygen is present (Shankar, Schlictman, and Chakrabarty 1995). We call this new combination the rnk-citT module, and it is what causes expression of the citT gene when oxygen is present, leading to the synthesis of the CitT transporter, and granting access to the citrate (Pos, Dimroth, and Bott 1998; Blount et al. 2012). ${ }^{5}$ This sort of genetic rewiring, in which a previously silent gene comes under the control of a new promoter, is called "promoter capture", and is one of the ways in which evolution innovates new traits (Adam, Dimitrijevic, and Schartle 1993; Usakin et al. 2005). 
The rnk-citT module is not a perfect solution to the problem of accessing the citrate resource because CitT does not just import citrate. Instead, CitT is an antiporter that ties citrate importation to the export of succinate and a few other related substances, chiefly malate and fumarate (Lutgens and Gottschalk 1980, Pos et al 1998). (CitT can also, strangely enough, import citrate while exporting citrate. As I said, it is not a perfect solution.) During fermentation this works perfectly well, because succinate is a principal waste product of citrate fermentation. However, succinate is not a waste product of aerobic citrate metabolism. Rather, it, malate, and fumarate are metabolic intermediates from which energy may still be derived. This is to say that it is still "food". And so Cit cells growing on citrate are a bit like a toddler learning to eat on its own. $\mathrm{Cit}^{+}$cells take a bite of citrate and chew it a bit, only to have most fall out of their mouths while taking the next bite of citrate. This has some interesting consequences. First, it means that $\mathrm{Cit}^{+}$cells do not derive as much benefit from growing on citrate as they might. Second, during growth on citrate, $\mathrm{Cit}^{+}$cells spill substantial amounts of succinate, malate, and fumarate into the medium, creating a new ecological opportunity ripe for evolutionary exploitation. Indeed, my colleague Caroline Turner determined that the $\mathrm{Cit}^{-}$cells that persisted in the population did so largely because they evolved the capacity to exploit this opportunity (Turner et al., In review).

Unlike Athena from Zeus's brow, new biological functions do not spring forth fully formed. Instead, they generally first arise in a barely functional form. Once a beneficial trait exists, mutations that improve it can be accumulated by natural selection. This "refinement" phase continues as long as the novel trait remains beneficial and new refining mutations arise. Unsurprisingly, early $\mathrm{Cit}^{+}$clones were very poor at growing on 
citrate, but the function improved substantially over time. We know that the evolution of $\mathrm{Cit}^{+}$cells to grow strongly on citrate first involved an increase in the number of rnk-citT modules present per genome, which in turn increased CitT production. We have yet to fully investigate the refinement that took place after $\mathrm{Cit}^{+}$cells became dominant. Almost certainly refinement will have involved mutations that improved usage of citrate. It also stands to reason that refinement will also involve the accumulation of mutations that permit $\mathrm{Cit}^{+}$cells to recover succinate, malate, and fumarate they spill into the medium during growth on citrate, and at least one refining mutation has already been discovered to do this (Quandt et al. 2014). Refinement will likely go on for thousands of generations, and involve many mutations, some of which may improve growth on citrate while reducing fitness on glucose. This would be a particularly interesting finding that would be consistent with ecological specialization driving incipient speciation in Ara-3 (Cohan and Perry 2007).

Potentiation has so far proven to very difficult to unravel even now that we know what mutations occurred during the population's history. (This is akin to a historian knowing what events occurred, but not knowing their impacts or relationships.) One problem is that the only phenotype that we know the potentiating mutations produce is the increased rate of mutation to $\mathrm{Cit}^{+}$, which gives us few practical means of linking particular mutations to potentiation. Further complicating matters, potentiation involved at least two mutations. During the replay experiments, clones from all three major clades in the population yielded $\mathrm{Cit}^{+}$mutants, but clones from Clade 3 were significantly more likely to do so. This pattern suggests that at least one potentiating mutation occurred 
before the clades diverged, and then at least one more occurred in Clade 3 (Blount et al. 2012). This is illustrated in Figure 3.

Another important question with which we are still struggling is that of how the potentiating mutations altered the potential to evolve $\mathrm{Cit}^{+}$. One possibility is that they physically promoted the occurrence of the actualizing mutation. Alternatively, the potentiating mutations were not needed for the actualizing mutation to occur, but had to be in place for it to produce the $\mathrm{Cit}^{+}$function (Blount, Borland, and Lenski 2008; Blount et al. 2012; Quandt et al. 2014). We call this second possibility "functional epistasis." Either mechanism would shed light on how evolutionary potential is altered by history. Physical promotion would relate to how mutations can change the range of possible future mutations. Functional epistasis, on the other hand, would speak not only to the role that epistasis plays in altering the effects of mutations, but it might also tell us something of how ecological interactions can alter evolutionary trajectories and potential. How so? The three clades in Ara-3 most likely coexisted by occupying different niches in the population's ecosystem. For instance, Clade 1 might have grown primarily on glucose, spilling a byproduct into the medium as it did so. Clade 2 might have subsisted on a combination of glucose and the byproduct, in the process releasing a second byproduct that Clade 3 used. Such specialization and cross-feeding has sustained diversity in other evolving microbial populations, including Ara-2 (Treves, Manning, and Adams 1998; Rozen, Schneider, and Lenski 2005).

Despite these problems, we have been making progress in unraveling the mysteries of potentiation. While we are still searching for the potentiating mutation common to Clades 1, 2, and 3, we have likely identified the potentiating mutation unique 
to Clade 3, and, as expected, it tells an interesting story (Quandt et al. 2015). The mutation is in the gltA gene that encodes citrate synthase, which links glycolysis, the pathway by which glucose is metabolized, to the Krebs cycle through which citrate is metabolized. This gltA mutation modified metabolism in a way that improved growth on acetate produced as a byproduct of growth on glucose by members of another clade, and upon which Clade 3 seems to have evolved to specialize. Coincidentally, the gltA mutation also made the rnk-citT module beneficial when it evolved. The second potentiating mutation therefore facilitated $\mathrm{Cit}^{+}$evolution via functional epistasis, and, consistent with my speculation above, was beneficial to Clade 3 in the niche it occupied in the pre-Cit ${ }^{+}$Ara-3 ecosystem. This means that $\mathrm{Cit}^{+}$evolution was also contingent in part upon the evolution of particular ecological conditions in the population.

\section{IMPLICATIONS OF THE Cit ${ }^{+}$STORY FOR THE ROLE OF HISTORICAL CONTINGENCY IN EVOLUTION}

That is the story of $\mathrm{Cit}^{+}$so far. Does it in and of itself resolve the controversy over the role of historical contingency in the grand pageant of evolution? Of course not. The very notion is silly. The LTEE is a highly simplified model system in which the environment never changes, the populations are insulated from the outside world, and evolution occurs strictly via the core evolutionary processes of mutation, drift, and natural selection. It does not involve many phenomena relevant to the issue of evolutionary contingency, including gene flow, complex ecology, climate change, mass extinction, or cataclysm ${ }^{6}$. (We have avoided any asteroid strikes in the lab so far. Knock on wood.) Nonetheless, the story of the historically contingent evolution of $\mathrm{Cit}^{+}$holds some interesting 
implications for the role of contingency in evolution. Perhaps the foremost is that, despite the LTEE's simplicity, the chanciness inherent to mutation and drift was sufficient to permit small but important differences to arise in the evolutionary and ecological histories of the populations along their broadly parallel trajectories. In the case of Ara-3, these differences shifted the population's evolutionary potential sufficiently that it eventually went down a path that has been wildly different from that of its brethren. ${ }^{7}$ If the chance and stochastic elements at the core of the evolutionary process can produce meaningful differences over the course of an evolutionary history under such strict conditions, then it would seem likely that contingency can play a significant role in determining the repeatability of evolutionary outcomes.

The evolution of the $\mathrm{Cit}^{+}$trait also suggests that evolutionary potential, also called "evolvability," or the capacity of a genotype to produce new heritable variation, is likely to be a more important factor in evolutionary contingency than has been considered so far (Pigliucci 2008). In the absence of gene flow, natural selection must act on variation that arises by mutation of an existing genotype, which may be envisioned as residing at a point in what could be called "variation space." The variation space surrounding a genotype is composed of variant genotypes that can arise from it by mutation. ${ }^{8}$ For any given genotype there exists a range of single, double, triple, or higher-tuple mutations that can occur at frequencies that range from very high to vanishingly, absurdly low. Those variant genotypes closest to the central genotype are those reachable by high frequency mutations, with progressively more distant variants being reachable only by the seven-league boots of progressively rarer mutations. 
As a genotype evolves, so too does the structure of the surrounding variation space, and the rates of the mutations necessary to reach different variants. Different variant genotypes encode different phenotypes, some of which will include novel traits. As the rates of the range of mutations from a genotype determine what variant genotypes are likely to occur, they likewise determine what novel traits may reasonably be evolvable. As with $\mathrm{Cit}^{+}$, a trait cannot evolve if the necessary variation does not arise. The prior evolutionary path taken by a lineage to which a genotype belongs determines where that genotype falls in variation space, and so determines what variation and what novel traits are evolvable from that genotype. In other words, the evolutionary path followed by a lineage over its history sets the "variation on what" side of the evolutionary equation, and not all variation is equally reachable from all genotypes. Prior history therefore plays a major role in determining what traits are accessible. Given the importance of novel traits in evolution, history can play a great role indeed in what future paths evolution is likely to take.

The actualization of the $\mathrm{Cit}^{+}$trait via the novel rnk-citT element points to another way in which history impacts evolutionary potential. François Jacob (1977) once observed that evolution innovates by making the new from the old, concluding that "to create is to recombine." The rnk-citT element is illustrative of how the modularity of the genome, together with the possibility for localized genetic duplication, allows preexisting genetic elements to be recombined and exapted for new functions (Ohno 1970; Gould and Vrba 1982; Whoriskey et al. 1987; Zhang 2003; Taylor and Raes 2004). These new combinations can produce new traits, not only by the shuffling of regulatory elements to alter gene expression, but also by rearranging parts of genes to create new 
proteins with novel functional combinations (Patthy 1999; True and Carroll 2002).

However, the range of new variation and traits that can be evolved in this manner, together with their consequences and the range of evolutionary trajectories they permit, depends critically upon the complement of recombinable genetic elements in a genome. That complement in turn depends on the prior evolutionary history that shaped and assembled the genome.

In the end, I think that my work on the evolution of the $\mathrm{Cit}^{+}$function in the LTEE shows that historical contingency arising from the core processes of evolution can impact evolutionary outcomes, and that there does seem to be a significant degree of path dependence to evolution, at least as pertains to novel traits. However, I again stress that the LTEE is a highly simplified system. The broader biological world is much more complex. In particular, the redundancy introduced by the astronomical number of evolving lineages and the incidence of gene transfer between them, at least at the microbial level, may mitigate the effect of contingency to a significant degree. Or it might not. The fact is that empirical investigation of evolutionary contingency has only just begun. Full resolution of the importance of contingency in evolution will require much more empirical, hypothesis-driven research, but this must not be a narrow program. It must instead be interdisciplinary and synthetic, involving collaboration between experimental evolutionists, systems, molecular, and field biologists, paleontologists, and, certainly not least, philosophers of science who can help parse tricky concepts, sharpen definitions, suggest questions, and help to design better research. Until such a concerted program of research has been carried out, I think it is far too premature to come to a solid 
conclusion. This may not be a satisfying note on which to end, but I think it is the proper one for now. 


\section{REFERENCES}

Adam, D., N. Dimitrijevic, and M. Schartle. 1993. “Tumor Suppression in Xiphophorus by an Accidentally Acquired Promoter." Science 259 (5096): 816-19.

Atkins, P. W. 1981. The Creation. San Francisco: W. H. Freeman.

Barrick, J. E., and R. E. Lenski. 2009. “Genome-Wide Mutational Diversity in an Evolving Population of Escherichia coli." Cold Spring Harbor Symposia on Quantitative Biology 74:119-29.

Barrick, J. E., D. S. Yu, S. H. Yoon, H. Jeong, T. K. Oh, D. Schneider, R. E. Lenski, and J. F. Kim. 2009. "Genome Evolution and Adaptation in a Long-Term Experiment with Escherichia coli." Nature 461:1243-47.

Beatty, J. 1993. “The Evolutionary Contingency Thesis.” In Concepts, Theories, and Rationality in the Biological Sciences: The Second Pittsburgh-Konstanz Colloquium in the Philosophy of Science, edited by G. Wolters, J. Lennox, and P. McLaughlin, 45-81. Pittsburgh: University of Pittsburgh Press.

—_. 2006. "Replaying Life's Tape.” Journal of Philosophy 103 (7):336-62.

Beatty, J., and I. Carrera. 2011. "When What Had to Happen was Not Bound to Happen: History, Chance, Narrative, Evolution." Journal of the Philosophy of History 5 (3):471-95.

Bedhomme, S., G. Lafforgue, and S. F. Elena. 2013. "Genotypic but not Phenotypic Historical Contingency Revealed by Viral Experimental Evolution.” BMC Evolutionary Biology 13:46. 
Bennett, A. F., and R. E. Lenski. 1993. "Evolutionary Adaptation to Temperature II. Thermal Niches of Experimental Lines of Escherichia coli." Evolution 47 (1):112.

Bentley, D. R. 2006. "Whole-Genome Resequencing." Current Opinion in Genetics and Development 16 (6):545-52.

Blaser, K. 1999. "The History of Nature and the Nature of History: Stephen Jay Gould on Science, Philosophy, and History." The History Teacher 32 (3):411-30.

Blount, Z. D. “History’s Windings in a Flask: Microbial Experiments into Evolutionary Contingency." In Chance in Evolution, edited by G. Ramsey and C. H. Pence. Chicago: University of Chicago Press. Forthcoming.

Blount, Z. D., J. E. Barrick, C. J. Davidson, and R. E. Lenski. 2012. “Genomic Analysis of a Key Innovation in an Experimental Escherichia coli Population.” Nature 489:513-18.

Blount, Z. D., C. Z. Borland, and R. E. Lenski. 2008. "Historical Contingency and the Evolution of a Key Innovation in an Experimental Population of Escherichia coli." Proceedings of the National Academy of Sciences (USA) 105 (23):78997906.

Bohannan, B. J. M., and R. E. Lenski. 2000. "Linking Genetic Change to Community Evolution: Insights From Studies of Bacteria and Bacteriophage.” Ecology Letters $3: 362-77$.

Burch, C. L., and L. Chao. 2000a. "Evolution by Small Steps and Rugged Landscapes in the RNA virus $\phi-6 . "$ Genetics 151 (3):921-27. 
- 2000b. "Evolvability of an RNA Virus is Determined by Its Mutational Neighborhood." Nature 406:625-28.

Chao, L., and E. C. Cox. 1983. "Competition Between High and Low Mutation Strains of Escherichia coli." Evolution 37 (1):125-34.

Chen, H. D., M. W. Jewett, and E. A. Groisman. 2011. "Ancestral Genes Can Control the Ability of Horizontally Acquired Loci to Confer New Traits.” PLOS Genetics 7:e1002184.

Cohan, F., and E. B. Perry. 2007. “A Systematics for Discovering the Fundamental Units of Bacterial Diversity.” Current Biology 17 (10):R373-86.

Conway Morris, S. 2003. Life's Solution. Cambridge: Cambridge University Press.

—. 2010. “Evolution: Like Any Other Science It Is Predictable.” Philosophical Transactions of the Royal Society B 365 (1537):133-45.

Cooper, T. F., and R. E. Lenski. 2010. "Experimental Evolution with E. coli in Diverse Resource Environments. I. Fluctuating Environments Promote Divergence of Replicate Populations.” BMC Evolutionary Biology 10:11.

Cooper, T. F., S. K. Remold, R. E. Lenski, and D. Schneider. 2008. “Expression Profiles Reveal Parallel Evolution of Epistatic Interactions Involving the CRP Regulon in Escherichia coli." PLoS Genetics 4:e35.

Cooper, T. F., D. E. Rozen, and R.E. Lenski. 2003. "Parallel Changes in Gene Expression After 20,000 Generations of Evolution in Escherichia coli." Proceedings of the National Academy of Sciences (USA) 100 (3):1072-77.

Cooper, V. S., and R. E. Lenski. 2000. "The Population Genetics of Ecological Specialization in Evolving E. coli Populations.” Nature 407:736-39. 
Cooper, V. S., D. Schneider, M. Blot, and R. E. Lenski. 2001. "Mechanisms Causing Rapid and Parallel Losses of Ribose Catabolism in Evolving Populations of $E$. coli B.” Journal of Bacteriology 183 (9):2834-41.

Covert, A. W., R. E. Lenski, C. O. Wilke, and C. Ofria. 2013. "Experiments on the Role of Deleterious Mutations as Stepping Stones in Adaptive Evolution." Proceedings of the National Academy of Sciences (USA) 110 (34):E3171-78.

Cox, G., F. Gibson, R. Luke, N. Newton, I. O’Brien, and H. Rosenberg. 1970. “Mutations Affecting Iron Transport in Escherichia coli.” Journal of Bacteriology 104 (1):219-26.

Crozat, E., T. Hindre, L. Kuhn, J. Garin, R. E. Lenski, and D. Schneider. 2011. “Altered Regulation of the OmpF porin by Fis in Escherichia coli During an Evolution Experiment between B and K12 strains.” Journal of Bacteriology 193 (2):429-40.

Crozat, E., N. Philippe, R. E. Lenski, J. Geiselmann, and D. Schneider. 2005. “LongTerm Experimental Evolution in Escherichia coli. XII. DNA Topology as a Key Target of Selection." Genetics 169 (2):523-32.

Crozat, E., C. Winkworth, J. Gaffe, P. F. Hallin, M. A. Riley, R. E. Lenski, and D. Schneider. 2010. "Parallel Genetic and Phenotypic Evolution of DNA Superhelicity in Experimental Populations of Escherichia coli." Molecular Biology and Evolution 27 (9):2113-28.

Dallinger, W.H. 1887. “The President's Address.” Journal of the Royal Microscopy Society 20 (2):184-99. 
Davis, B. D. 1949. “The Isolation of Biochemically Deficient Mutants of Bacteria by Means of Penicillin." Proceedings of the National Academy of Sciences (USA) 35 (1):1-10.

Davis, B. D., and E. S. Mingioli. 1950. "Mutants of Escherichia coli Requiring Methionine or Vitamin B12." Journal of Bacteriology 60 (1):17-28.

Dawkins, R. 1996. The Blind Watchmaker. New York: Norton.

de Queiroz, A., and J. A. Rodriguez-Robles. 2006. "Historical Contingency and Animal Diets: The Origins of Egg Eating in Snakes.” The American Naturalist 167 (5):682-92.

Desjardins, E. 2011. "Historicity and Experimental Evolution.” Biology and Philosophy 26:339-64.

de Visser, J. A. G. M., C. W. Zeyl, P. J. Gerrish, J. L. Blanchard, and R. E. Lenski. 1999. "Diminishing Returns from Mutation Supply Rate in Asexual Populations." Science 283 (5400):404-6.

Drake, J. W. 1991. “A Constant Rate of Spontaneous Mutation in DNA-based Microbes.” Proceedings of the National Academy of Sciences (USA) 88 (16):7160-64.

Elena, S. F., and R. E. Lenski. 2003. "Evolution Experiments with Microorganisms: The Dynamics and Genetic Bases of Adaptation.” Nature Reviews Genetics 4:457-69. Elena, S. F., R. Sanjuan, A. V. Borderia, and P. E. Turner. 2001. “Transmission Bottlenecks and the Evolution of Fitness in Rapidly Evolving RNA Viruses." Genetics and Evolution 1 (1):41-48. 
Emerson, S. B. 2001. “A Macroevolutionary Study of Historical Contingency in the Fanged Frogs of Southeast Asia." Biological Journal of the Linnean Society 73 (1):139-51.

Flores-Moya, A., M. Rouco, M. J. Garcia-Sanchez, C. Garcia-Balboa, R. Gonzalez, E. Costas, and V. Lopez-Rodas. 2012. "Effects of Adaptation, Chance, and History on the Evolution of the Toxic Dinoflagellate Alexandrium minutum under Selection of Increased Temperature and Acidification." Ecology and Evolution 2 (6):1251-59.

Foote, M. 1998. “Contingency and Convergence.” Science 280 (5372):2068-69.

Fox, J.W. and R.E. Lenski. 2015. "From Here to Eternity - The Theory and Practice of a Really Long Experiment.” PLoS Biology doi:10.1371/journal.pbio.1002185.

Frost, G., and H. Rosenberg. 1973. “The Inducible Citrate-Dependent Iron Transport System in Escherichia coli K-12.” Biochimical et Biophysica Acta 330 (1):90 101.

Fukami, T., H. J. E. Beaumont, X. X. Zhang, and P. B. Rainey. 2007. “Immigration History Controls Diversification in Experimental Adaptive Radiation." Nature $446: 436-39$.

Gould, S. J. 1985. "The Paradox of the First Tier: An Agenda for Paleobiology." Paleobiology 11 (1):2-12.

- 1989. Wonderful Life. New York: Norton. 1991. "The Disparity of the Burgess Shale Arthropod Fauna and the Limits of Cladistics Analysis: Why We Must Strive to Quantify Morphospace.” Paleobiology 17 (4):411-23. 
2002. The Structure of Evolutionary Theory. Cambridge, MA: Belknap Press of Harvard University Press.

Gould, S. J., and E. S. Vrba. 1982. "Exaptation—A Missing Term in the Science of Form." Paleobiology 8 (1):4-15.

Hall, B. G. 1982. "Chromosomal Mutation for Citrate Utilization by Escherichia coli K12." Journal of Bacteriology 151 (1):269-73.

Härle, C., I. Kim, A. Angerer, and V. Braun. 1995. "Signal Transfer Through Three Compartments: Transcription Initiation of the Escherichia coli Ferric Citrate Transport System from the Cell Surface.” The EMBO Journal 14 (7):1430-38.

Hegreness, M., and R. Kishony. 2007. “Analysis of Genetic Systems Using Experimental Evolution and Whole-Genome Sequencing." Genome Biology 8:201.

Herring, C. D., J. D. Glasner, and F. R. Blattner. 2003. "Gene Replacement Without Selection: Regulated Suppression of Amber Mutations in Escherichia coli." Gene 311:153-63.

Hussein, S., K. Hantke, and V. Braun. 1981. "Citrate-Dependent Iron Transport System in Escherichia coli K-12.” European Journal of Biochemistry 117 (2):431-37.

Ishiguro, N., C. Oka, Y. Hanazawa, and G. Sato. 1979. "Plasmids in Escherichia coli Controlling Citrate-Utilizing Ability." Applied and Environmental Microbiology $38(5): 956-64$.

Ishiguro, N., C. Oka, and G. Sato. 1978. "Isolation of Citrate Positive Variants of Escherichia coli from Domestic Pigeons, Pigs, Cattle, and Horses." Applied and Environmental Microbiology 36 (2):217-22. 
Jablonski, D. 1986. "Background and Mass Extinctions: The Alternative of Macroevolutionary Regimes.” Science 231 (4734):129-33.

Jacob, F. 1977. “Evolution and Tinkering." Science 196 (4295):1161-66.

Jeong, H., V. Barbe, C. H. Lee, D. Vallenet, D. S. Yu, S. H. Choi, A. Couloux, S. W. Lee, S. H. Yoon, L. Cattolico, C. G. Hur, H. S. Park, B. Ségurens, S. C. Kim, T. K. Oh, R. E. Lenski, F. W. Studier, P. Daegelen, and J. F. Kim. 2009. “Genome Sequences of Escherichia coli B Strains REL606 and BL21(DE3).” Journal of Molecular Biology, 394 (4):644-53.

Kaçar, B., and E. A. Gaucher. 2013. "Experimental Evolution of Protein-Protein Interaction Networks." Biochemistry Journal 453 (3):311-19.

Kawecki, T. J., R. E. Lenski, D. Ebert, B. Hollis, I. Olivieri, and M. C. Whitlock. 2012. "Experimental Evolution.” Trends in Ecology and Evolution 27 (10):547-60.

Koser, S. A. 1924. "Correlation of Citrate-Utilization by Members of the ColonAerogenes Group with Other Differential Characteristics and with Habitat.” Journal of Bacteriology 9 (1):59-77.

Kussell, E. 2013. "Evolution in Microbes." Annual Review of Biophysics 42 (1):493-514. Lara, F. J. S., and J. L. Stokes. 1952. "Oxidation of Citrate by Escherichia coli." Journal of Bacteriology 63 (3):415-20.

le Gac, M., J. Plucain, T. Hindre, R. E. Lenski, and D. Schneider. 2012. "Ecological and Evolutionary Dynamics of Coexisting Lineages During a Long-Term Experiment with Escherichia coli." Proceedings of the National Academy of Sciences (USA) 109 (24):9487-92. 
Leiby, N., and C. J. Marx. 2014. "Metabolic Erosion Primarily through Mutation Accumulation, and not Tradeoffs, Drives Limited Evolution of Substrate Specificity in Escherichia coli." PLOS Biology 12 (2):e1001789.

Lenski, R. 2004. "Phenotypic and Genomic Evolution during a 20,000-Generation Experiment with the Bacterium Escherichia coli." Plant Breeding Reviews 24 (2):225-65.

Lenski, R. E., and B. R. Levin. 1985. "Constraints on the Coevolution of Bacteria and Virulent Phage: A Model, Some Experiments, and Predictions for Natural Communities." American Naturalist 125 (4):585-602.

Lenski, R. E., M. R. Rose, S. C. Simpson, and S. C. Tadler. 1991. "Long-Term Experimental Evolution in Escherichia coli. I. Adaptation and Divergence During 2000 Generations.” American Naturalist 138 (6):1315-41.

Lenski, R. E., and M. Travisano. 1994. "Dynamics of Adaptation and Diversification: 10,000-Generation Experiment with Bacterial Populations." Proceedings of the National Academy of Sciences (USA) 91 (15):6808-14.

Lenski, R.E., M.J. Wiser, N. Ribeck, Z.D. Blount, J.R. Nahum, J.J. Morris, L. Zaman, C.B. Turner, B.D. Wade, R. Maddamsetti, A. Burmeister, E. Baird, J. Bundy, N. Grant, K. Card, M. Rowles, K. Weatherspoon, S.E. Papoulis, R. Sullivan, C. Clark, J.S. Mulk, and N. Hajela. In press. "Sustained Fitness Gains and Variability in Fitness Trajectories in the Long-Term Evolution Experiment with Escherichia coli." Proceedings of the Royal Society, London B.

Lewontin, R. C. 1966. “Is Nature Probable or Capricious?" BioScience 16 (1):25-27. 
—. 1974. The Genetic Basis of Evolutionary Change. New York: Columbia University Press.

Losos, J. B. 2010. “Adaptive Radiation, Ecological Opportunity, and Evolutionary Determinism." The American Naturalist 175 (6):623-39.

Losos, J. B., T. R. Jackman, A. Larson, K. de Querioz, and L. Rodriguez-Schettino. 1998. "Contingency and Determinism in Replicated Adaptive Radiations of Island Lizards.” Science 279 (5359):2115-18.

Luria, S. E., and M. Delbrück. 1943. "Mutations of Bacteria from Virus Sensitivity to Virus Resistance.” Genetics 28 (6):491-511.

Lutgens, M., and G. Gottschalk. 1980. "Why a Co-Substrate is Required for Anaerobic Growth of Escherichia coli on Citrate." Journal of General Microbiology 199 (1):63-70.

Maddamsetti, R., R.E. Lenski, and J.E. Barrick. “Adaptation, Clonal Interference, and Frequency-Dependent Interactions in a Long-Term Evolution Experiment with Escherichia coli. Genetics 200 (2):619-631.

Mani, G. S., and B. C. Clarke. 1990. "Mutational Order: A Major Stochastic Process in Evolution." Proceedings of the Royal Society of London B 240 (1297):29-37.

Monod, J. 1971. Chance and Necessity. New York: Alfred A. Knopf.

Meyer, J. R., A. A. Agrawal, R. T. Quick, D. T. Dobias, D. Schneider, and R. E. Lenski. 2010. "Parallel Changes in Host Resistance to Viral Infection during 45000 Generations of Relaxed Selection.” Evolution 64 (10):3024-34. 
Meyer, J. R., D. T. Dobias, J. S. Weitz, J. E. Barrick, R. T. Quick, and R. E. Lenski. 2012. "Repeatability and Contingency in the Evolution of a Key Innovation in Phage Lambda." Science 335 (6067):428-32.

Meyer, J. R., and R. Kassen. 2007. "The Effects of Competition and Predation on Diversification in a Model Adaptive Radiation." Nature 446:432-35.

Ohno, S. 1970. Evolution by Gene Duplication. New York: Springer.

Orgogozo, V. "Replaying the Tape of Life in the Twenty-First Century." Interface Focus $5: 2015057$.

Papadopoulos, D., D. Schneider, J. Meier-Eiss, W. Arber, R. E. Lenski, and M. Blot. 1999. "Genomic Evolution during a 10000-Generation Experiment with Bacteria." Proceedings of the National Academy of Sciences (USA) 96 (7):380712.

Patthy, L. 1999. "Genome Evolution and the Evolution of Exon-Shuffling-A Review." Gene 238 (1):103-14.

Pelosi, L., L. Kuhn, D. Guetta, J. Garin, J. Geiselmann, R. E. Lenski, and D. Schneider. 2006. "Parallel Changes in Global Protein Profiles during Long-Term Experimental Evolution in Escherichia coli." Genetics 173 (4):1851-69.

Perfeito, L., L. Fernandes, C. Mota, and I. Gordo. 2007. “Adaptive Mutations in Bacteria: High Rates and Small Effects.” Science 317 (5839):813-15.

Philippe, N., E. Crozat, R. E. Lenski, and D. Schneider. 2007. "Evolution of Global Regulatory Networks During a Long-Term Experiment with Escherichia coli." BioEssays 29 (9):846-60. 
Philippe, N., L. Pelosi, R. E. Lenski, and D. Schneider. 2009. "Evolution of PenicillinBinding Protein 2 Concentration and Cell Shape During a Long-Term Experiment with Escherichia coli." Journal of Bacteriology 191 (3):909-21.

Pigliucci, M. 2008. “Is Evolvability Evolvable?” Nature Reviews Genetics 9:75-82.

Plucain, J., T. Hindre, M. le Gac, O. Tenaillon, S. Cruveiller, C. Medigue, N. Leiby, W.R. Harcombe, C.J. Marx, R. E. Lenski, and D. Schneider. 2014. "Epistasis and allele specificity in the emergence of a stable polymorphism in Escherichia coli." Science 343 (6177):1366-1369.

Pos, K. M., P. Dimroth, and M. Bott. 1998. "The Escherichia coli Citrate Carrier CitT: A Member of a Novel Eubacterial Transporter Family Related to the 2Oxoglutarate-Malate Translocator from Spinach Chloroplasts." Journal of Bacteriology 180 (16):4160-65.

Quandt, E. M., D. E. Deatherage, A.D. Ellington, G. Georgiou, and J. E. Barrick. 2014. "Recursive Genomewide Recombination and Sequencing Reveals a Key Refinement Step in the Evolution of a Metabolic Innovation in Escherichia coli." Proceedings of the National Academy of Sciences (USA) 111 (6):2217-22.

Quandt, E.M., J. Golihar, Z.D. Blount, A.D. Ellington, G. Georgiou, and J.E. Barrick. 2015. "Fine-tuning citrate synthase flux potentiates and refines metabolic innovation in the Lenski evolution experiment." eLife 2015;10.7554/eLife.09696 Reynolds, C. H., and S. Silver. 1983. "Citrate Utilization by Escherichia coli: Plasmidand Chromosome-Encoded Systems." Journal of Bacteriology 180 (3):4160-65. 
Rozen, D. E., and R. E. Lenski. 2000. “Long-Term Experimental Evolution in Escherichia coli. VIII. Dynamics of a Balanced Polymorphism.” The American Naturalist 155 (1):24-35.

Rozen, D. E., N. Philippe, J. A. de Visser, and D. Schneider. 2009. “Death and Cannibalism in a Seasonal Environment Facilitate Bacterial Coexistence.” Ecology Letters 12 (1):34-44.

Rozen, D. E., D. Schneider, and R. E. Lenski. 2005. "Long-Term Experimental Evolution in Escherichia coli. XIII. Phylogenetic History of a Balanced Polymorphism.” Journal of Molecular Evolution 61 (2):171-80.

Scheutz, F., and N. A. Strockbine. 2005. "Genus I. Escherichia, Castellani and Chalmers 1919." In Bergey's Manual of Systematic Bacteriology. Vol. 2, The Proteobacteria, edited by G. M. Garrity, D. J. Brenner, and J. R. Staley, 607-24. New York: Springer.

Shankar, S., D. Schlictman, and A. M. Chakrabarty. 1995. "Regulation of Nucleoside Diphosphate Kinase and an Alternative Kinase in Escherichia coli: Role of the sspA and rnk Genes in Nucleoside Triphosphate Formation." Molecular Microbiology 17 (5):935-43.

Sniegowski, P., P. Gerrish, and R. Lenski. 2000. "Evolution of High Mutation Rates: Separating Causes from Consequences.” BioEssays 22 (12):1057-66.

Spor, A., D. J. Kvitek, T. Nidelet, J. Martin, J. Legrand, C. Dillmann, A. Bourgais, D. de Vienne, G. Sherlock, and D. Sicard. 2014. "Phenotypical and Genotypic Convergences Are Influenced by Historical Contingency and Environment in Yeast." Evolution 68 (3):772-90. 
Sterelny, K., and P. Griffiths. 1999. Sex and Death: An Introduction to Philosophy of Biology. Chicago: The University of Chicago Press.

Studier, F. W., P. Daegelen, R. E. Lenski, S. Maslov, and J. F. Kim. 2009.

"Understanding the Differences between Genome Sequences of Escherichia coli B Strains REL606 and BL21(DE3) and Comparison of the E. coli B and K-12 Genomes." Journal of Molecular Biology 394 (4):644-52.

Szendro, I. G., J. Franke, J. A. G. M. de Visser, and J. Krug. 2013. "Predictability of Evolution Depends Nonmonotonically on Population Size." Proceedings of the National Academy of Sciences (USA) 110 (2):571-76.

Taylor, J. S., and J. Raes. 2004. "Duplication and Divergence: The Evolution of New Genes and Old Ideas.” Annual Review of Genetics 28:615-43.

Travisano, M., J. A. Mongold, A. F. Bennett, and R. E. Lenski. 1995. “Experimental Tests of the Roles of Adaptation, Chance, and History in Evolution.” Science 26 (5194):87-90.

Travisano, M., F. Vasi, and R. E. Lenski. 1995. "Long-Term Experimental Evolution in Escherichia coli. III. Variation Among Replicate Populations in Correlated Responses to Novel Environments.” Evolution 49 (1):189-200.

Treves, D. S., S. Manning, and J. Adams. 1998. "Repeated Evolution of an AcetateCrossfeeding Polymorphism in Long-Term Populations of Escherichia coli." Molecular Biology and Evolution 15 (7):789-97.

True, J. R., and S. B. Carroll. 2002. "Gene Co-Option in Physiological and Morphological Evolution." Annual Review of Cellular and Developmental Biology 18:53-80. 
Turner, C.B., Z.D. Blount, and R.E. Lenski. 2015. Replaying Evolution to Test the Cause of Extinction of One Ecotype in an Experimentally Evolved Population. PLoS One doi:101371/journal.pone.0142050

Turner, C.B., Z.D. Blount, D.H. Mitchell, and R.E. Lenski. In review. "Evolution and Coexistence in Response to a Key Innovation in a Long-Term Evolution Experiment with Escherichia coli." Evolution.

Usakin, L. A., G. L. Kogan, A. I. Kalmykova, and V. A. Gvozdev. 2005. “An Alien Promoter Capture as a Primary Step of the Evolution of Testes-Expressed Repeats in the Drosophila melanogaster Genome." Molecular Biology and Evolution 22 (7):1555-60.

Van Valen, L. M. 1991. “Biotal Evolution: A Manifesto.” Evolutionary Theory 10:1-13. Vasi, F., M. Travisano, and R. Lenski. 1994. "Long-Term Experimental Evolution in Escherichia coli. II. Changes in Life-History Traits During Adaptation to a Seasonal Environment." The American Naturalist 144 (3):432-56.

Vermeij, G. J. 2006. "Historical Contingency and the Purported Uniqueness of Evolutionary Innovations.” Proceedings of the National Academy of Sciences (USA) 103 (6):1804-9.

Weinreich, D. M., N. F. Delaney, M. A. DePristo, and D. L. Hartl. 2006. “Darwinian Evolution Can Follow Only Very Few Mutational Paths to Fitter Proteins.” Science 312 (5770):111-14.

Weinreich, D. M., R. A. Watson, and L. Chao. 2005. "Sign Epistasis and Genetic Constraint on Evolutionary Trajectories.” Evolution 59 (6):1165-74. 
Whoriskey, S. K., V. Nghiem, P. Leong, J. Masson, and J. H. Miller. 1987. “Genetic Rearrangements and Gene Amplification in Escherichia coli: DNA Sequences at the Junctures of Amplified Gene Fusions." Genes and Development 1:227-37.

Wilke, C. O., J. L. Wang, C. Ofria, R. E. Lenski and C. Adami. 2001. "Evolution of Digital Organisms at High Mutation Rates Leads to Survival of the Flattest." Nature 412:331-33.

Wiser, M. J., N. Ribeck, and R. E. Lenski. 2013. "Long-Term Dynamics of Adaptation in Asexual Populations.” Science 342 (6164):1364-67.

Woods, R., D. Schneider, C. L. Winkworth, M. A. Riley, and R. E. Lenski. 2006. “Tests of Parallel Molecular Evolution in a Long-Term Experiment with Escherichia coli." Proceedings of the National Academy of Sciences (USA) 103 (24):9107-22.

Wright, S. 1988. "Surfaces of Selective Value Revisited.” American Naturalist 131 (1):115-23.

Zhang, J. 2003. "Evolution by Gene Duplication: An Update.” Trends in Ecology and Evolution 18 (6):292-98. 
${ }^{1}$ In microbiology, a clone is a population grown from a single founding cell. Because of asexual reproduction, this population will be more or less genetically identical, meaning that we can study its properties to understand the properties of the founding cell. Due to this genetic homogeneity, we also tend to use "clone" interchangeably with "genotype." ${ }^{2}$ In essence, parallel replay experiments look at whether or not populations starting from the same initial evolutionary state then take parallel evolutionary paths when evolving under the same conditions. Another class of experiments, "historical difference experiments," is designed to examine whether or not populations that start from different evolutionary states follow convergent paths to a common evolutionary endpoint during evolution in the same conditions (Travisano et al. 1995a, Blount forthcoming; Spor et al. 2014).

${ }^{3}$ Citrate was not added to DM25 to provide an ecological opportunity, but has always been an ingredient of DM-type media (Davis and Mingioli 1950). DM was originally formulated by the bacteriologist Bernard Davis when he was developing a method of isolating mutants of $E$. coli that exploits the fact that penicillin only kills actively growing cells (Davis 1949). When penicillin is added to a culture of bacteria growing in a minimal medium the only cells that are not killed are those that are not actively growing because they have mutations that prevent them from synthesizing all nutrients not provided by the medium, and therefore are not actively growing. Davis found citrate increased the killing efficiency of penicillin, so he included it in his standard recipe. Davis's penicillin method of mutant isolation came into wide use in the 1950s, which in turn led to DM becoming a widely used minimal growth medium for other applications. 
We now know that the citrate in DM improves the availability of iron for E. coli. At neutral $\mathrm{pH}$ with oxygen present, iron occurs primarily as an insoluble ferric ion. Citrate binds to ferric ions to form a stable, soluble complex called ferric dicitrate. E. coli has a transport system that specifically allows it to bind ferric dicitrate, and take up the iron, though not the citrate, from it (Cox et al. 1970; Frost and Rosenberg 1973; Hussein, Hantke, and Braun 1981; Härle et al. 1995).

E. coli requires a tiny amount of citrate to take up iron, as little as $10 \mu \mathrm{M}$. DM25 contains $1700 \mu \mathrm{M}$. Why the excess? First, DM was designed specifically by Davis (1949) for his penicillin method of isolating mutants, which he knew worked better with citrate. Because E. coli was not known to use citrate at all, Davis likely did not think it was terribly important to find the lowest effective citrate level. Second, citrate's role in iron acquisition was not discovered until the 1970s (Frost and Rosenberg 1973). In short, DM was developed for a particular experimental method long before the biological role of citrate in the medium had been discovered and the concentrations strictly necessary for it to fulfill that role had been determined, and its recipe reflects this. The high concentration of citrate in DM25 and the large ecological opportunity it presents in the LTEE was therefore contingent upon its unique history combined with conservative lab practice.

${ }^{4}$ This is to say that there may be alternate mutations that carry the same adaptive benefit, but that do not simultaneously exist on the pathway leading to the historically contingent trait.

${ }^{5} \mathrm{The} \mathrm{Cit}^{+}$mutants recovered during the replay experiments show that there were actually many possible actualizing mutations. All of them have mutations that involve $\operatorname{cit} T$, and most clearly place copies of cit $T$ under the control of new promoters, but the actual 
mutations vary considerably. Many are tandem duplications similar to that found in the original $\mathrm{Cit}^{+}$variant, and more of these form are variants of the rnk-citT module, but several place cit $T$ under the control of other promoters. Could these alternate actualizing mutations have changed what evolutionary paths $\mathrm{Cit}^{+}$evolution might have taken? Good question. I don't know. (Yet.)

${ }^{6}$ Or perhaps it has experienced a small one. The $\mathrm{Cit}^{-}$lineage that persisted in the Ara-3 population after $\mathrm{Cit}^{+}$became dominant went extinct between 43,500 and 44,000 generations. Careful study by Turner et al. (2015) showed that the extinction was not a deterministic matter of competitive exclusion of $\mathrm{Cit}^{-}$subsequent to niche invasion by a $\mathrm{Cit}^{+}$subpopulation. $\mathrm{Cit}^{-}$clones from just prior to extinction were able to reinvade the population even thousands of generations later, showing that the $\mathrm{Cit}^{-}$niche was still open. Moreover, when replicates of the population started from samples taken prior to $\mathrm{Cit}^{-}$ extinction were evolved for five hundred generations, no instances of extinction were observed. These findings led to the conclusion that the extinction was caused by an unknown environmental perturbation to which the $\mathrm{Cit}^{-}$subpopulation was more sensitive, the LTEE version of a chance cataclysm. Not only does this represent another instance in which contingency has played a role in the $\mathrm{Cit}^{+}$story, its impact is ongoing. $\mathrm{Cit}^{+}$ evolution in Ara-3 after the extinction takes place in an ecosystem substantially altered by loss of $\mathrm{Cit}^{-}$. How contingent might its subsequent evolutionary trajectory be upon the extinction event? This is a question we will be able to assess in the future. One of the extinction replay experiments, founded from a population sample frozen at 43,000 generations, was chosen to be continued indefinitely as the thirteenth LTEE population, 
Ara-7. It will permit comparison of how $\mathrm{Cit}^{+}$has evolved under conditions in which the $\mathrm{Cit}^{-}$extinction did or did not take place. Stay tuned.

${ }^{7}$ What if the $\mathrm{Cit}^{+}$function were to evolve in another of the LTEE populations? Would this mean that $\mathrm{Cit}^{+}$is not a contingent trait? I don't think so. My work pretty well demonstrates that the trait's evolution was dependent upon the occurrence of the potentiating mutations, which in turn means that it was contingent upon the occurrence of an evolutionary history that included such mutations. The recurrence of such a history in another population would not negate the trait's contingency. Speaking in terms of path dependence, such a recurrence would still argue that $\mathrm{Cit}^{+}$is path dependent, but that there was not a single path upon which it was dependent. This is an important pointevolutionary path dependence, and thereby historical contingency, exists on a continuum ranging from those outcomes that may be reached via one or a few paths, to those that are path-insensitive and guaranteed.

${ }^{8}$ This concept is similar that of the "genetic neighborhood," which deals with a genotype and the local region of genotypic space that contains genotypes one or two steps removed from it (Lewontin 1974; Wilke et al. 2001; Covert et al. 2013). The two concepts are related, but my idea with variation space is that is that all points in the genotypic landscape are reachable at a certain probability determined by the frequency of the necessary mutation or mutations. Variation space thus deals with how the accessibility of different points in genotypic space varies. 


\section{FIGURES}
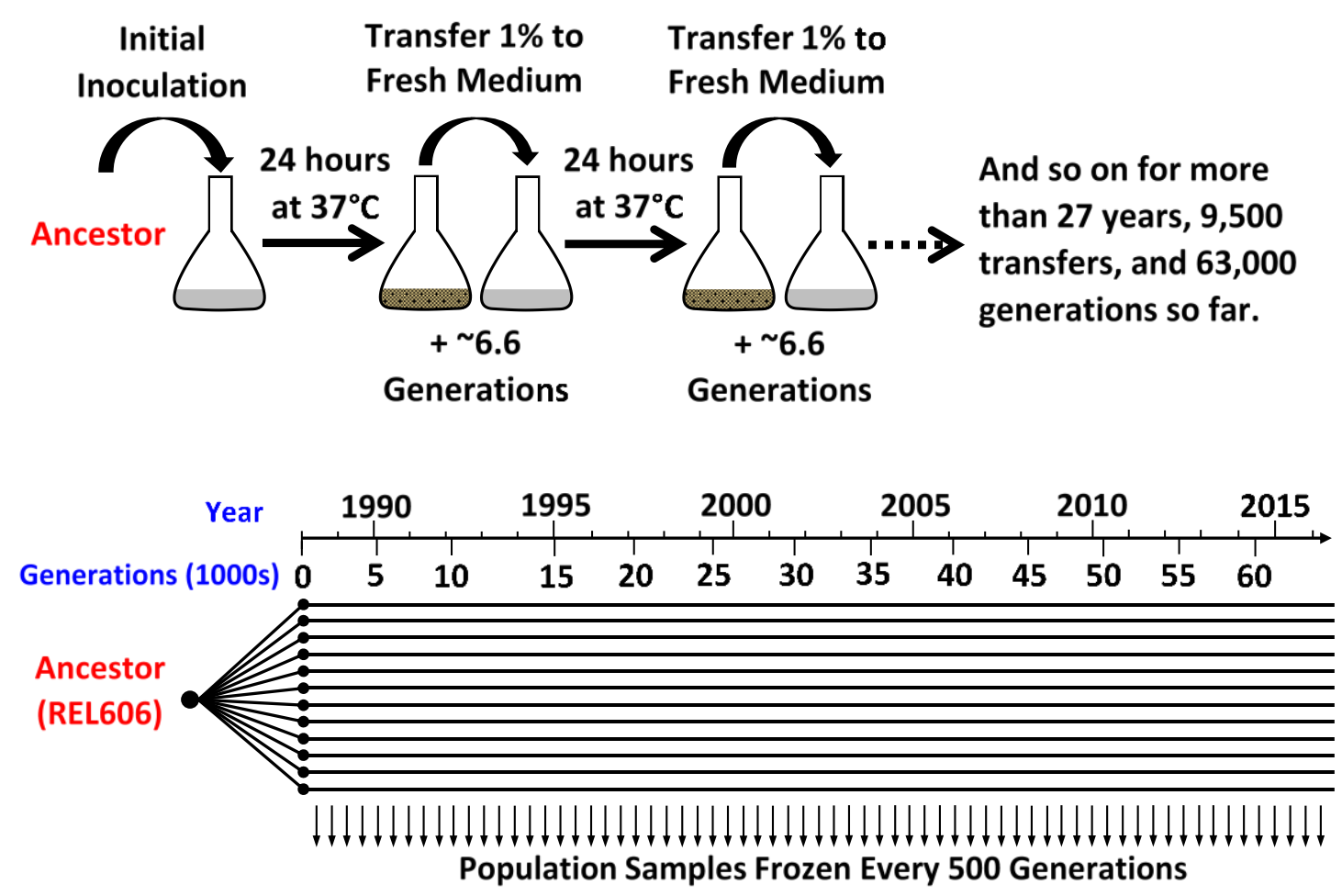

Figure 1. The E. coli Long-Term Evolution Experiment (LTEE).

The LTEE involves a simple serial transfer regime (top). $1 \%$ of each population is transferred to a fresh volume of growth medium DM25 every 24 hours, after which the populations are incubated for another 24 hours. Each population experiences approximately 6.6 generations per day. The experiment includes twelve, initially identical populations that have been evolved in parallel, with viable samples of each frozen every 500 generations (bottom). 

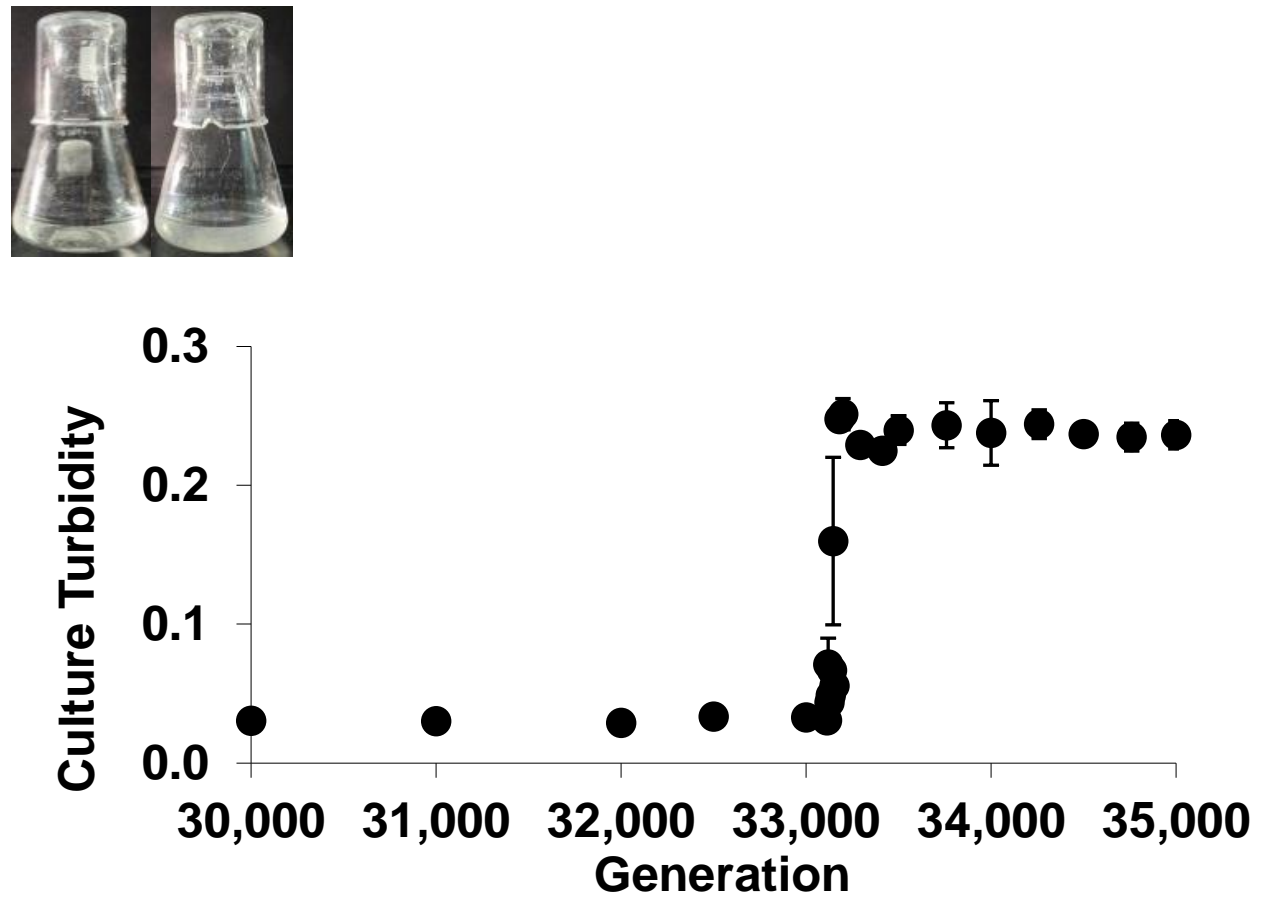

Figure 2. Expansion of the Ara-3 Population.

As $\mathrm{Cit}^{+}$variants rose to high frequency, the size of the Ara-3 population expanded several-fold due to the high concentration of citrate in the DM25 growth medium. The expansion caused the population to become much more turbid after twenty-four hours of incubation. (Figure adapted from Blount et al. 2012) 


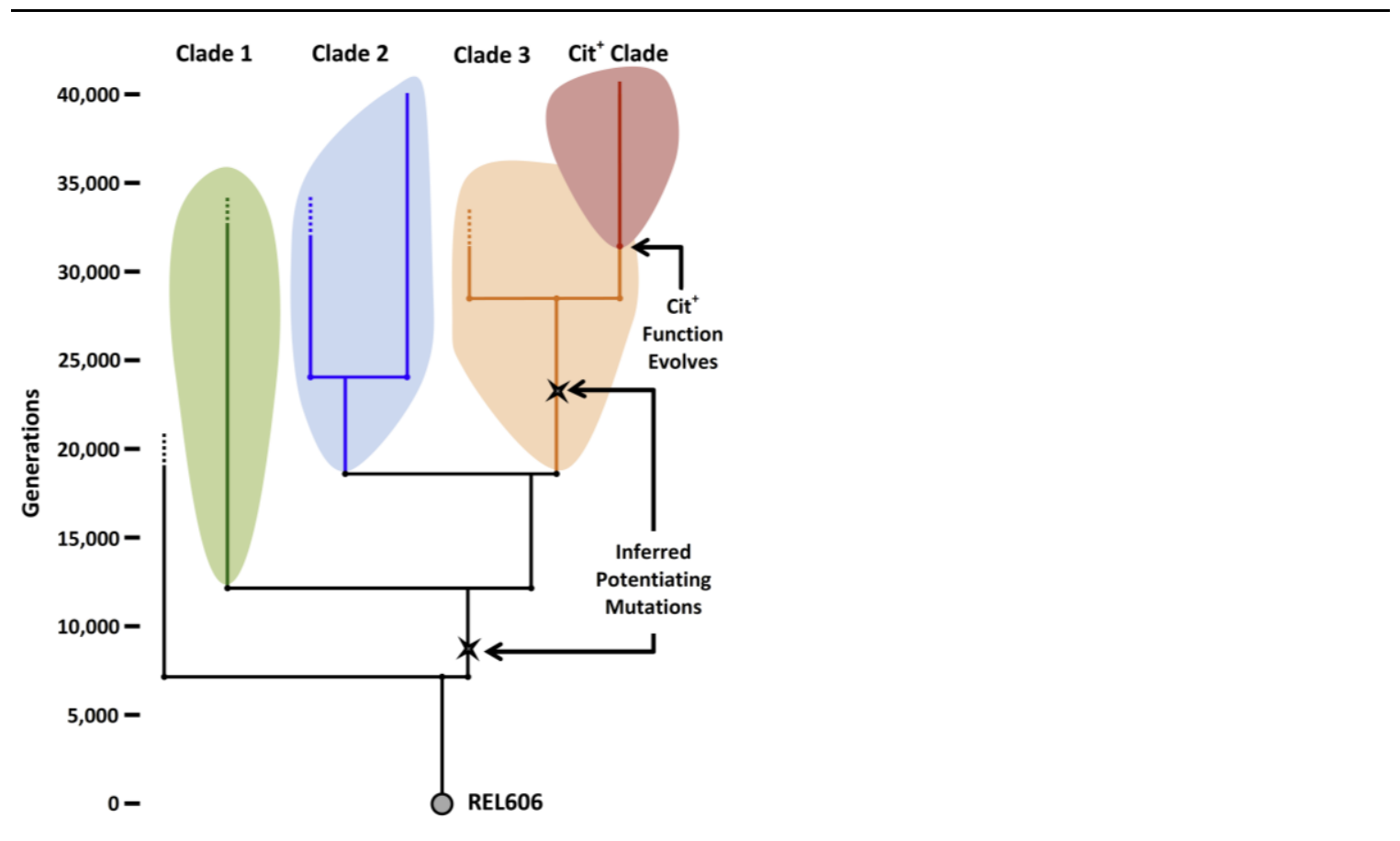

Figure 3. Phylogeny of the Ara-3 Population.

Population phylogeny based on sequenced clonal genomes. Colored lines and shaded areas correspond to major identified clades. (Figure adapted from Blount et al. 2012)

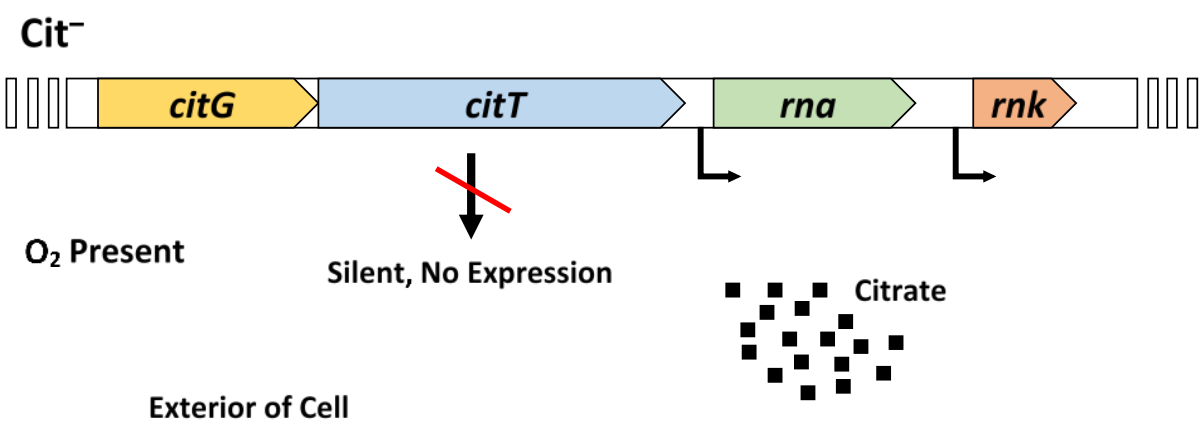

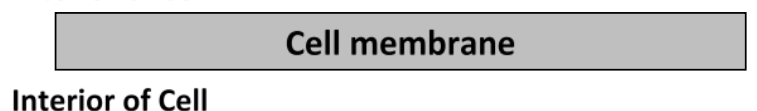




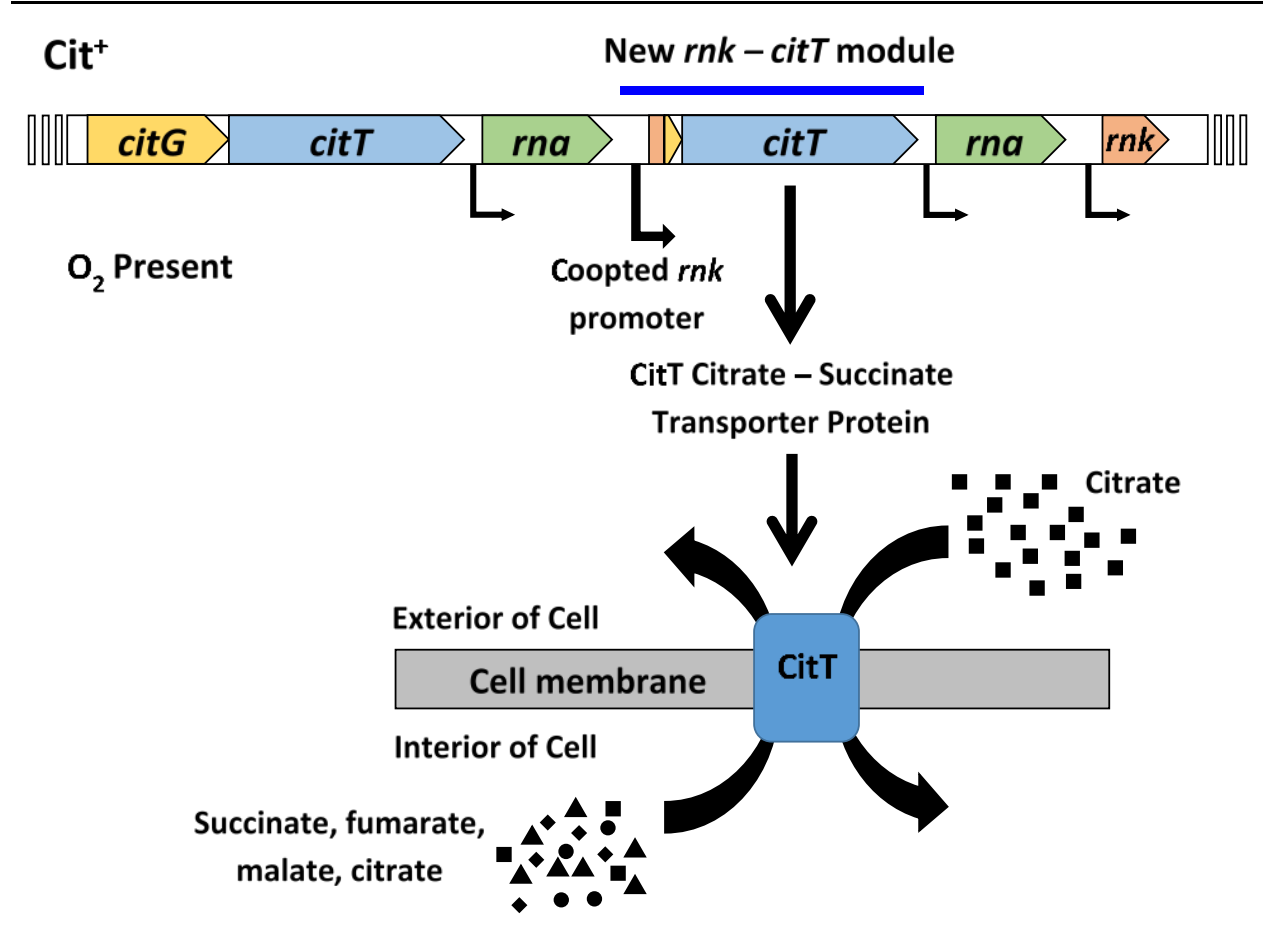

Figure 4. $\mathrm{Cit}^{+}$Actualization.

In the $\mathrm{Cit}^{-}$ancestor (top), the $c i t T$ gene is silent when oxygen is present. In $\mathrm{Cit}^{+}$genomes (bottom), a tandem duplication places a new copy of citT adjacent to and under the control of the promoter that normally controls the aerobically expressed $r n k$ gene. The new rnk-citT module supports the expression of the CitT citrate-succinate transporter protein when oxygen is present, providing access to the citrate resource. (Figure adapted from Blount et al. 2012.) 